DOI: http://dx.doi.org/10.12660/gvcasosv8n2c12

\title{
KARIGHANA ALLIANCE: DEVELOPING A SOCIAL BALANCED SCORECARD TO MONITOR THE BREAK-EVEN
}

KariGhana Alliance: desenvolvendo um social balanced scorecard para monitorar o break-even

BENJAMIN GADBOIS - benjamin.gadbois@ gmail.com

HEC Montreal - Montréal, Canada

DAVID MolinA - david.molina@ hec.ca

HEC Montreal - Montréal, Canada

MAIRA PeTrini - maira.petrini@ pucrs.br

Pontifícia Universidade Católica do Rio Grande do Sul - Porto Agre, RS, Brasil

MARLEi Pozzebon - marlei.pozzebon@ @ec.ca

Escola de Administração de Empresas de São Paulo da FGV - São Paulo, SP, Brasil

HEC Montreal - Montréal, Canada

Submissão: 09/10/2018 | Aprovação: 16/12/2018

\begin{abstract}
KariGhana Alliance is a social business operating in the shea industry since 2012. One of the first objectives of the KariGhana Alliance was to bring together women working in the informal shea sector, in order to improve their economic and social situation, as well as their health. In order to be financially sustainable, the company has met with a team of consultants who suggested creating a social balanced scorecard (SBSC). SBSC could serve as an efficient tool to meet the company's goals: 1) improve the women's quality of life and 2) to achieve the company's break-even.
\end{abstract}

Keywords: social business, social enterprise, shea sector, sustainability, social balanced scorecard.

\section{Resumo}

A KariGhana Alliance é uma empresa social que atua no setor de carité desde 2012. Um dos primeiros objetivos da KariGhana Alliance era reunir mulheres que trabalham informalmente no setor de carité, a fim de aumentar sua situação econômica e social, bem como sua saúde. Para ser sustentável, a empresa se reuniu com uma equipe de consultores que sugeriu a criação de um balanced scorecard social (SBSC). O SBSC poderia servir como uma ferramenta eficiente para atingir os objetivos da empresa: 1) melhorar a qualidade de vida das mulheres e 2) alcançar o ponto de equilíbrio da empresa.

Palavras-chave: negócio social, empresa social, setor de carité, sustentabilidade, social balanced scorecard social.

\section{Introduction}

In the beginning of December 2018, the board of directors of KariGhana Alliance ${ }^{1}$ is meeting a team of consultants from a specialized agency in order to establish a new strategy for the coming years. Among the major challenges: to convince investors to continue supporting KariGhana Alliance until the company achieves its break-even. Understanding the specificities of the social

\footnotetext{
${ }^{1}$ For anonymity purposes, the authors have decided to modify the names mentioned in the original document.
} 
business model, one of the consultants suggest a social balanced scorecard (SBSC) as an interesting way to set up an efficient strategy for KariGhana Alliance, for both internal and external purposes.

Setting up a SBSC project for a social business like KariGhana Alliance would help the company to achieve its dual bottom-line objectives, such as social benefits for the women in Ghana and a financial break-even, helping the company to have a better communication for the investors in the long run. In order to face this mandate, the consultants started by plunging into the history of KariGhana Alliance, trying to grasp its creation, context of development, challenges and opportunities.

\section{Ghana and the Shea Sector}

The Republic of Ghana, most commonly called Ghana, is a Western African country located at the border of the Gulf of Guinea. Its capital is Accra and its official currency is the "cedi", represented by the symbol GHS. The currency rate in 2018 is 4,668 GHS for 1 \$US. Ghana is divided in ten regions; one of them is the "Great North", the place where KariGhana Alliance was born. Over there, the poverty rate is the highest in the country, from $52.3 \%$ to $87.8 \%$ depending on the areas. According to the World Bank, people are living there with less than 1.25 USD per day. Surrounded by Ivory Coast, Burkina Faso and Togo, Ghana is one of the only countries in this part of Africa where English is the official language, instead of French.

Among the most important economic activities in the Northern Ghana, we found the shea sector, which is growing fast in the last years. Indeed Ghana is among the top exporters of shea in Africa. For instance their current production is around 130'000 ton per year. Compared to others, Ghana's shea kernel is valued for its high stearin and its total fat content. According to some studies, 55 percent of the shea production is used for domestic consumption (especially for cooking but also creams, medicinal or oil). The other 45 percent are used for export, generally for food and confectionary, but also sometimes for cosmetic (10\% of the export). According to "West Africa Democracy Radio", government of Ghana relies on shea to reduce the development gap between the north and the south. Being operated by local inhabitants following outdated technologies, the shea production was not profitable for the country.

Even if women in Northern Ghana represent $80 \%$ of the agricultural workforce and they are working twice as much as men, they rarely own the lands (See Figure 1). This masculinity in the culture of Ghana is also influencing the income management for households. In 2012, there was still a lot to improve on the condition of women and on the reduction of poverty in Ghana.

\section{The creation of KariGhana Alliance}

In 2012, a new project appeared in the rural communities of the Northern Ghana. The project was an initiative aimed to bring together women working in the informal shea sector in order to improve their economic and social situation as well as their health. This project was then called KariGhana Alliance, proposing to develop a product and organizational innovation in the informal shea sector (See Figure 2).

The KariGhana Alliance's objective was to gather 4500 women within the first three years of the project. An increase in the revenues of women producers from $20 \%$ to $30 \%$ was predicted by developing a social model capable of assuring its viability. Three years after its implementation, 5000 women have been working together and received training for a good quality treatment of shea nuts and butter. Shea butter (karité) is a natural fat extract taken from the nut of the shea tree - an oak-like tree found only in the arid savannah regions of Africa. Since its first year in November 2013, KariGhana Alliance has sold 93 tons of nuts at a high price to a global leader in agricultural product logistic. In 2016, 220 tons of shea nuts were sold to an oil producer and 64 tons of butter to European clients. However, there is still some restraints to the project, like the access and the 
KARIGHANA ALLIANCE: DEVELOPING A SOCIAL BALANCED SCORECARD TO MONITOR... Benjamin Gadbois, David Molina, Maira Petrini, Marlei Pozzebon

efficiency of local and global markets, as well as creating new financial products in order to address the lack of liquidities during poorest seasons.

Figure 1. Women working in crops

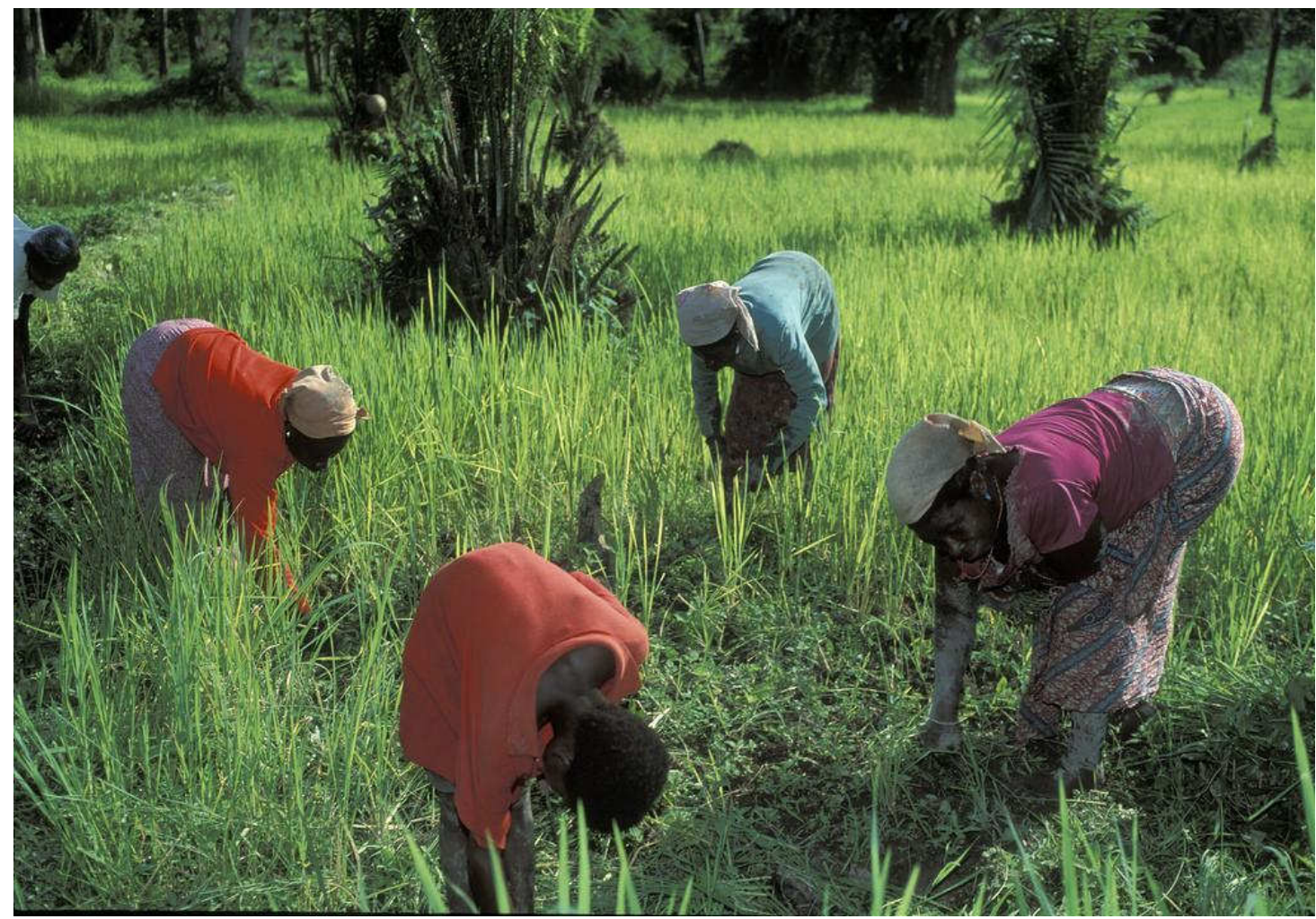

Source: World Bank. (2007). Women doing work on crops [Image]. Retrieved from https://www.flickr.com/photos/worldbank/2073350635

Figure 2. Shea nuts

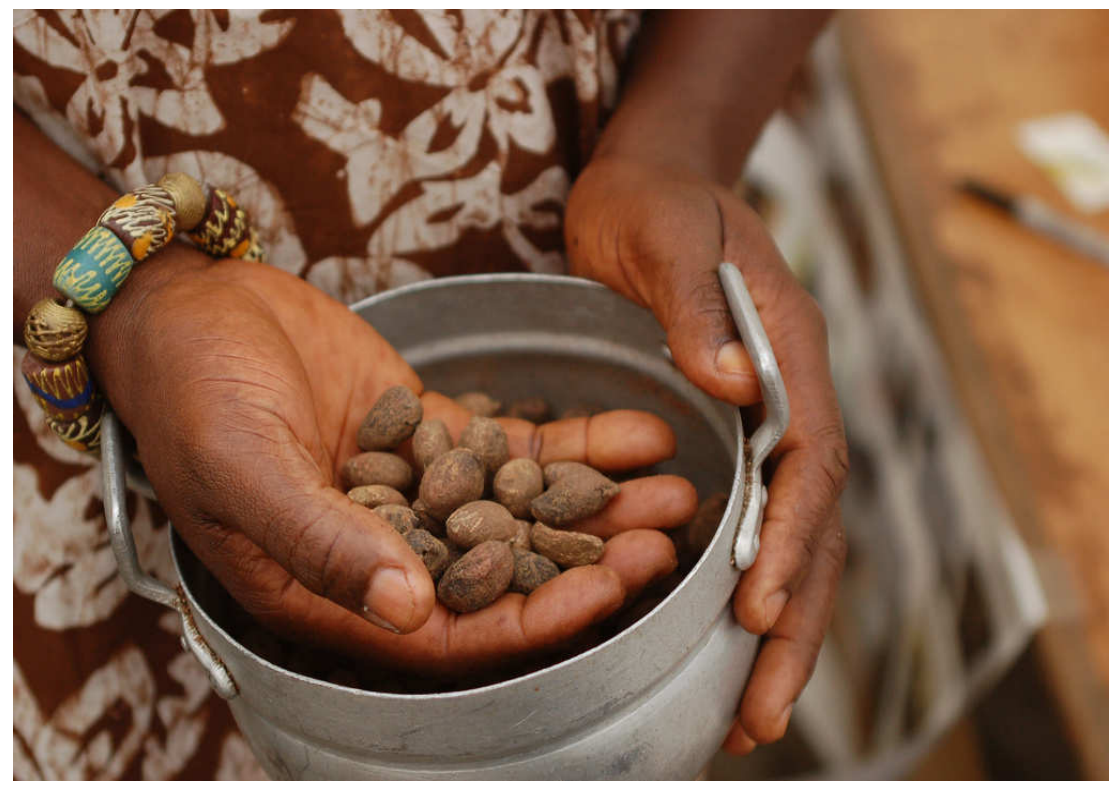

Source: Hersman, E. (2009). Shea Nut Extraction [Image]. Retrieved from https://www.flickr.com 


\section{A network of women before all}

Started in 2012 to help 1,500 women in rural Northern Ghana manage to grow their shea nut business, the newly named KariGhana Alliance has grown to a network. The women from the network were divided in groups according to their location, in order to occupy all the lands owned by the organization, being managed by coordinators. These coordinators were trained to transfer their knowledge to women, especially on the importance of the quality when they had to gather shea nuts. In that sense, KariGhana Alliance women were somehow dependent of their coordinators to communicate with other women of other groups in the region. Often coming from the same sector, from the same tribe, the coordinators are the informational link between the organization and the network of 'shea' women.

Since 2014, KariGhana Alliance employs about 25 permanent staff. Most of KariGhana Alliance's team is working on the field in 11 areas across Northern Ghana. Their mission, besides training, is to register women of KariGhana Alliance, organize logistics, traceability and payment. The office staff also has an accounting department and a marketing team. Its CEO is a woman expert in strategy consulting and African markets.

A partnership allowed by an international software company (ISC), an international microfinance institution (PoziFinance) and local associations

In order to develop a social business in the shea sector, a hybrid complementary partnership was created between an NGO focusing on microfinance (PoziFinance), two local microcredit institutions (MeenGhana and Matadu) and a software company (ISC). The shea project in Ghana is the first joint initiative of the partnership between ISC \& PoziFinance to create sustainable business models through access to microfinance, education, and information technology. PoziFinance and ISC have combined their supply chain and development expertise to create a value chain reinforcement program.

ISC is a company offering software solutions to hold and improve operations and decisional processes of businesses. It allows people and organizations to work together more productively with a better use of commercial knowledge in order to stay ahead of competition. Part of their product consists of integrative platforms for mobile, according to their clients' needs. Moreover, ISC is oriented toward sustainable development, and it has created a transversal function within its processes in order to ensure the well accomplishment of all missions of the firm at every level. Several key values of sustainable development and innovation are integrated in all of their products, their operations and social investments. ISC helped KariGhana Alliance to develop a reliable supply chain, gave the social business a dedicated software and also kept supporting the business with an interest-free loan, thereby KariGhana Alliance is no longer dependent on donations and can now focus on its financial sustainability.

PoziFinance on the other hand, defines itself as a charity international association whose mission is to "fight against poverty through the development of microfinance in order to improve the access to financial services for poor populations which generally can't afford these kind of services". Created in France, its activities are present within around 80 different countries where they propose consulting services and technical assistance to microfinance players as well as support program to entrepreneurs. The purpose behind its activities is to improve their financial and social performances. Moreover, they contribute to the evolution of microfinance and the diffusion of good practices. To sum up, PoziFinance seeks to promote the development of innovative projects and share their knowledge for transversal projects within three area of expertise: (a) microfinance and consulting for innovation and technical support: (b) microfinance to reinforce microfinance businesses impact; (c) microfinance and knowledge capitalized on expertise to professionalize the sector. 
In that way, PoziFinance is proud to improve the financial situation of populations in Europe, Africa and South-East Asia. More precisely, in the KariGhana Alliance's case, PoziFinance has capitalized on training - the twelve coordinators being paid by the NGO - and on work capital when creating KariGhana Alliance initiative. Concerning the transition toward KariGhana Alliance, PoziFinance has planned to transfer their best coordinators toward the new social business.

The profile of ISC and PoziFinance is summarized in Table 1. These organizations are the founders of the KariGhana Alliance and they have had support of two local microcredit institutions partners: MeenGhana and Matadu.

Table 1. Profile of ISC and PoziFinance

\begin{tabular}{|c|c|}
\hline ISC & PoziFinance \\
\hline $\begin{array}{l}\text { - ISC is a world-leading provider of business } \\
\text { software, based in Europe. } \\
\text { - Delivers products and services that help } \\
\text { accelerate business innovation. } \\
\text { - ISC has customers in more than } 10020 \\
\text { countries. } \\
\text { - Deep knowledge of business processes. }\end{array}$ & $\begin{array}{l}\text { - PoziFinance is an international non-profit } \\
\text { organization (NGO), based in France. } \\
\text { - Mission: To alleviate poverty through } \\
\text { development of microfinance. } \\
\text { - Provides services to microfinance institutions } \\
\text { (MFIs). } \\
\text { - Microfinance: provision of financial services e.g. } \\
\text { credits to low-income clients }\end{array}$ \\
\hline
\end{tabular}

\section{MeenGhana, Matadu and their involvement in KariGhana Alliance}

They are also connected to two NGOs of the region that defend women's groups. The first is a Northern Ghana NGO, which support women's living conditions. The second is an international NGO, which helps reducing poverty in more than 40 countries, by linking people to information capital and markets and helping farmers improve the quantity and quality of their crops in Ghana.

MeenGhana is an NGO whose mission is to reduce poverty through access to microfinance and new technologies. They are often located in the most remote regions and activated a following process to account for the number of people involved in their program in order to verify that it is really the poorest that are affected. The NGO works with the people of Ghana since 2011 and is now financing MeenGhana and the Matadu foundation. It is important to mention that in Africa, women are part of the poorest population and are then the most targeted by the foundation. In fact their customers in Ghana are women only. The NGO also works within alimentary security, nutrition and education. The Ghanaian financial services providers reported this year a positive growth in the borrower level, driven by NGOs and banks.

The last microfinance enterprise that helped in the creation of KariGhana Alliance is Matadu. It is an NGO working for women participation in North Ghana. Their goal is to promote social welfare for women in the operational sector through the development of local businesses. They try to improve women's rights by economic emancipation thanks to microcredit loans to support profitgenerating activities for women - which would improve their standards of living and that of their families. Besides, the Matadu Association gathers information and encourages the development of activist women group in Northern Ghana. For example, they offer a meeting to initiate discussions about rural development and activities related to women. Apart from that, they also provide an English and mathematics training to counterbalance the analphabetism problem. Finally, they also wish to educate women about sociocultural questions such as teenager pregnancy, women and children health, abuse of drugs, HIV and traditional practices.

In brief, the social business was first initiated by the partnership with ISC and PoziFinance, along with local associations. It allows to create a sustainable program for women in the Northern 
Ghana through access to microfinance, education and information technology. This partnership allows PoziFinance and ISC to provide a more reliable supply chain and development expertise to KariGhana Alliance.

\section{How KariGhana Alliance works}

By gathering the women into a labeled association and providing the technology, training, microfinance and so on, PoziFinance and ISC ensured that women can work under better conditions with an increasing awareness of the right way to collect and process the nuts. Consequently, they can offer a better product quality so they can get a better price on the market.

\section{A sustainable business model to the benefit of shea harvesters}

The ISC solution helps create a reliable supply chain, which generates for both buyers and sellers the security of being able to buy predictable amounts of produce at a stable quality and fair price. A mobile application scans and traces each sack of shea nuts and each box of shea butter, which provides the product traceability demanded by global export markets. In addition, the software can send price and market information straight to the buyers' mobile phone. As per June 2016, the project succeeded help 1,500 women in rural Northern Ghana manage in reaching over 10,000 women; quality was there so the training was paying off.

Each with its own specialty, ISC and PoziFinance are complementary. The NGO ensures that women receive the training, tools and microcredit allowing the best possible realization of their work. For its part, ISC provides technological solutions in terms of adapted software. For instance, a cocktail of barcodes, cellphones and software allows women and buyers to know the quantities and market prices, which, in return, has the effect of increasing their confidence in KariGhana Alliance.

In fact, a key point to know is that the women are not formal employees of KariGhana Alliance. No contract is binding on both parties. The operating mode is that KariGhana Alliance is positioned as an intermediary in the marketing chain for the purpose of increasing the profit margin of Ghanaian women (See Figure 3. KariGhana Alliance value chain). Specifically, it tries to remove the small players who offer a lower price to the women for their nuts, which they accept to fulfill their immediate needs.

Figure 3. KariGhana Alliance value chain

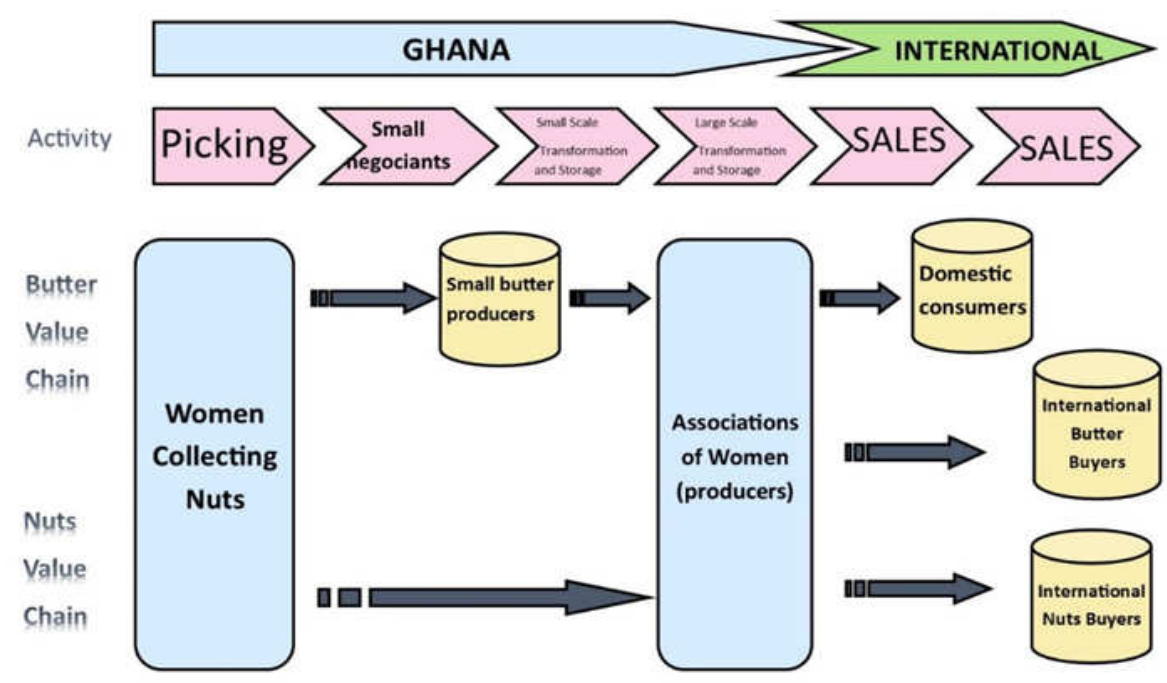




\section{KariGhana Alliance Value Chain}

In this context, the choice of selling or not to KariGhana Alliance comes to the women, since the organization cannot prevent them from selling to small buyers. Thus, the organization must make every effort to create and enhance the women's loyalty. The success achieved during the first three years demonstrates the great potential of this organization. Certainly, KariGhana Alliance always had the wind in its sails for it to be a Social Business.

To continue on the same momentum and to ensure its economic survival, KariGhana Alliance will pay a fee on each bag and butter box it buys directly from the "Shea women" (Ghanaian women who collect the Shea nuts). According to the CEO of KariGhana Alliance, the premium price that they will get for the quality justifies the additional fee. Nevertheless, being in its early stages, the company must also validate its actions to its investors and stakeholders by successfully performing its role as an intermediary that concretely helps Ghanaian women. Table 2 shows the different activities of KariGhana Alliance.

Table 2. Activities of KariGhana Alliance

\begin{tabular}{|c|l|}
\hline 1 & $\begin{array}{l}\text { Organize women shea nut and butter processors into federated women's producer } \\
\text { associations, facilitate the functioning of those associations and establish a shea network. }\end{array}$ \\
\hline 2 & $\begin{array}{l}\text { Facilitate the access of women to health services and establish community-level social } \\
\text { funds to enable women to manage their livelihood risks. }\end{array}$ \\
\hline 3 & $\begin{array}{l}\text { Facilitate the improvement of shea product quality and value, while increasing women's } \\
\text { processing safety and productivity. }\end{array}$ \\
\hline 4 & $\begin{array}{l}\text { Effectively link up the women's shea products with the market and strengthen the efficiency } \\
\text { of the shea supply chain. }\end{array}$ \\
\hline 6 & $\begin{array}{l}\text { Provide technical support to partner MFIs to refine and develop new credit products for } \\
\text { clients, enabling them to acquire appropriate business inputs, pay the premium of the NHIS } \\
\text { and stabilize their incomes throughout the year. }\end{array}$ \\
\hline $\begin{array}{l}\text { Drive an awareness campaign to promote the protection and productivity of shea trees, } \\
\text { support women's economic and human rights and educate communities on the need to } \\
\text { involve women in household decision making. }\end{array}$ \\
\hline
\end{tabular}

\section{The current situation of KariGhana Alliance}

In September 2017, KariGhana Alliance enrolled around 15,000 women, divided in 716 groups. These women collected nuts in the areas of Gushegu, Savelugu, Karaga, Nanumba North, West Mamprusi, Bole, Sawla South and North, Tuna East and West, Bolgatanga. Their spoken dialects are Dagbani, Komkomba, Manpurli, Dagaari, Wale, Frafra and many others. MeenGhana and Matadu are still financing women groups through microcredits.

They are still offering different butter and nut qualities, such as pure unrefined shea butter, refined butter depending of client specifications and raw nuts. For the 2016-2017 period, they expected a production of 2000 metric tons in 2016 and 3000 MT in 2017 for nuts and 300 MT in 2016 for butter. They are currently certified by recognized entities such as organizations promoting and giving access to fair trade programs and certification. 


\section{Processing High Quality butter}

Shea butter is produced with improved quality nuts, which have been collected and processed by the women groups of the KariGhana Alliance. All shea butter processors of the KariGhana Alliance are also nut processors. Through training, the women have been taught how to improve their traditional techniques, from the collection of the nuts to the ideal packaging of the butter. They have been taken through all the processing stages to ensure that all steps are followed to produce topquality butter (See Figure 4).

Figure 4. Processing High Quality Shea Butter

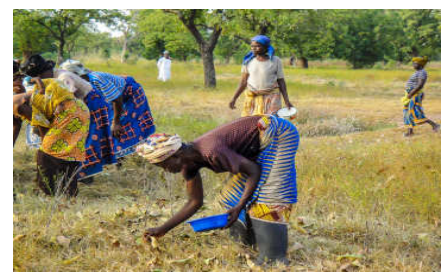

1. Collecting

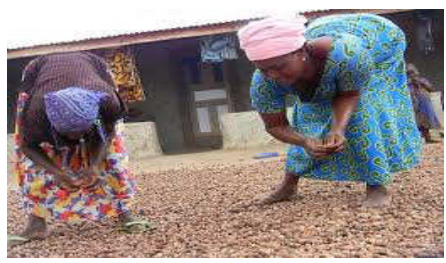

4. First Drying

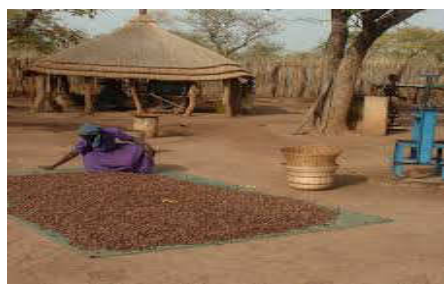

7. Second Drying

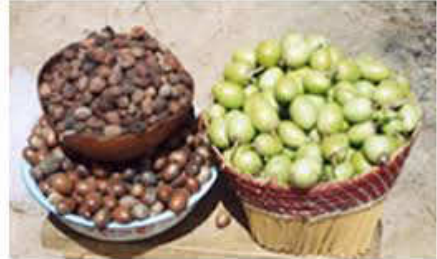

2. De-pulp

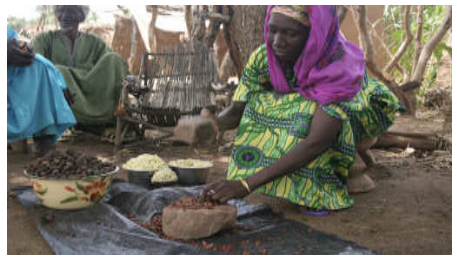

5. De-Husk

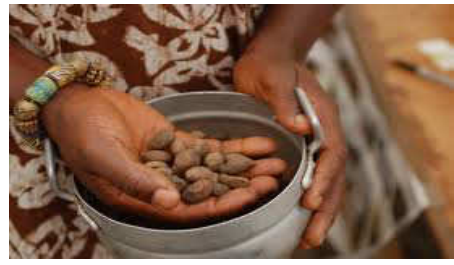

8. Checking moisture

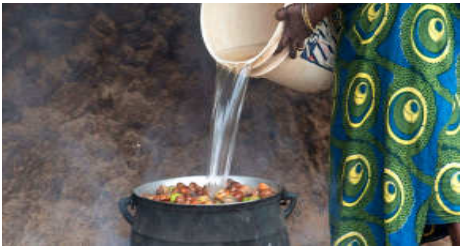

3. Boiling

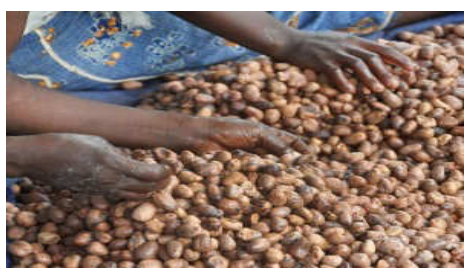

6. Sorting

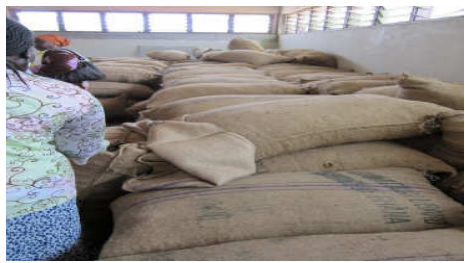

9. Storing

\section{Employees' remuneration}

KariGhana Alliance is a social business, which might be seen as a "mission-centric social enterprise" with a social mission in perfect agreement with the organization activities. Indeed, training, microcredit and buying their "products" at a premium price are all activities with a potential social impact on Ghanaian women. The microcredit, trainings, pre-financing, among others, are activities offered to women.

Certainly, these women are the purpose of this Social Business; therefore, in order to gain their loyalty, it is important to build a relationship of trust. For us to verify that level of trust, we have measured the percentage of bags of butter sold to KariGhana Alliance. It is obtained by dividing the quantity sold to KariGhana Alliance by the total quantity sold. The goal is to get as close as possible to $100 \%$. However we were not able to verify this quantity because of the lack of available data.

Women are not direct employees of KariGhana Alliance. They have the liberty of selling their stock to whomever they want. However, productivity is both an advantage for them and a good indicator of the success of the training. Regarding the past results about productivity for Shea kernel, 
the average woman collects three bags per year. However, the CEO of KariGhana Alliance would like to increase that number to six bags in the coming years. Besides, in order to get the premium price, it is essential for the women to be able to recognize the good Shea kernels. This is only possible once the nuts have been boiled and dried. In fact, it is KariGhana Alliance' responsibility to bring this crucial information to women for them to get more than the regular price. Put another way, PoziFinance and ISC have done research about Shea kernel and Shea butter production to develop a Shea market analysis. Consequently, KariGhana Alliance knows what crucial information they need to put into the training in order to meet international buyer exigencies. We can call it the businessrelated knowledge of training and it includes know-how that is only useful for Shea nuts processes.

\section{Expenses and Revenues}

In order for KariGhana Alliance to enter the shea butter market, the organization had to work on bringing awareness to the women, so they could understand the importance of quality. These women are now fully aware that improving the quality of the products will automatically increase their revenue and consequently improve their quality of life. Besides, when working together, these women are able to produce and sell more, while having the support and assistance that they need. As a result, the Shea women are now making a profit of ten dollars per 100 kilograms instead of gaining only two dollars for the same quantity.

Concerning Shea women's capacity to wait until the market price increases, it is one of the important aspects that KariGhana Alliance has to deal with if it wants to increase women's loyalty. Indeed, one of the reasons why women don't always sell their bags to KariGhana Alliance is the urgency of satisfying their immediate needs. So when small intermediary buyers pass by, women often agree to sell, regardless of the lower price they get. Their financial situation impels them to accept the money. We talk here of pre-financing, it means that KariGhana Alliance pays a woman for her bag before the right market time to sell, even if it is not yet sold to a customer, but at the regular market price. A few weeks later, when Shea kernels' value rises in the market, KariGhana Alliance sells the bags to customers. In addition, a relevant detail of this pre-financing process is that Shea women offer premium quality kernels so the price is higher than the regular one. Consequently, KariGhana Alliance only gives the difference between premium and regular prices to Shea women once a customer agrees to it.

In order to achieve the goal of the financial break-even, Global Shea Alliance must have 14,000 Ghanaian women in its ranks regarding to its business plan. For now, this Social Business has 15,000 women registered, but this number was reached with great effort and is not stable. The challenge is to maintain and to increase this number. Again, it is important to understand that these women are not forced to sell to KariGhana Alliance. In fact, this organization acts as an intermediary in the marketing chain so no contract binds the two actors. Consequently, this entity must capitalize on building a strong relationship of trust with these women to ensure their loyalty.

\section{$\underline{\text { Education }}$}

The amount of training sessions constitute a good means of attracting and retaining more women. Indeed, when a coordinator carries out training in a new village or community, he or she generates curiosity among the women and, thus, enhances KariGhana Alliance's reputation. There have been cases where some of the Shea women did not attend the training meetings. As soon as they realized how behind they were comparing to the others who attended, this became an incentive for them not to miss the next one. Therefore, the number of training sessions given is an interesting measure to illustrate the effort put forth by the organization to educate Shea women. Thus, the gradual increase here demonstrates the importance KariGhana Alliance gives to meeting the knowledge needs of newcomers. 
Finally, training is delivered once to each women group. This means that the women who have already received it will be overlooked concerning new learning features of the training. However, this can also be considered advantageous since coordinators could ask women already trained the following questions:

- Excluding your Shea work life part, what learning dimensions of the training also had an impact on your life?

- Would you have liked to learn more about those dimensions?

- In order to help you in your day-to-day life, what knowledge would be good to add in the training?

The first will disclose all the lifestyle related knowledge; the second will enable KariGhana Alliance to know which features need to be improved for future newcomer training; and the third will provide learning ideas that can be added to the training content in order to achieve the indicator objective. Therefore, this small survey could allow KariGhana Alliance to know all the lifestylerelated knowledge and whether or not it is sufficiently explained. Finally, it gives suggestions to further improve the lives of women, and it shows women's opinions are taken into account.

\section{$\underline{\text { Technologies }}$}

Turning to health, PoziFinance is currently developing a new project to foster financial protection in the event of the unforeseen. This initiative is being developed because the Ghanaian national insurance is too expensive for Shea women. Therefore, PoziFinance is developing a "Community Social Fund" to encourage women to financially protect themselves in the event of death, illness, etc. Consequently, each community will have its own fund for easy access to the money when desired.

Accordingly, KariGhana Alliance tries to provide financial protection and a better understanding for women to manage their capital. Shea women explained that they are very grateful for KariGhana Alliance because they are now aware of the real production costs. Before the presence of this organization, women didn't pay attention to wood utilization, transportation, water cost and so on. Now by doing so, they empower themselves. According to the project Coordinator at PoziFinance, women have needs in terms of liquidity for two main reasons. The first is to be able to sell their stock at the right market time and the second is to buy adequate equipment to prevent injuries and enable a better quality offering.

Another issue is that women may walk several kilometers to collect the shea nuts. It is therefore crucial for them to wear protective gears in order to reduce the chances of injuries by snakes or other animals. To address the situation, KariGhana Alliance, through PoziFinance, offered microloans to allow them to buy the necessary equipment with an interest-free loan.

A general goal for KariGhana Alliance is to improve the quality of life of Ghanaian women. Whether buying Shea butter or Shea nuts, KariGhana Alliance intends to provide a minimum increase of $25 \%$ of their revenues through premium pricing.

\section{Buyers' relations}

For customers, the association previously developed by KariGhana Alliance had three main objectives involving customer satisfaction: 1) ensure quality by providing training and tools to women; 2) be able to provide a large amount at the desired time for the customer; and 3) traceability: be able to know exactly where one's stock is. In fact, the technology provided by ISC allows the client to know the quantities and also to track inventory through the barcode placed on each bag or butter box. Concerning the product quality, the customer pays only after the reception of the product and it is only after analyzing the quality that he agrees, or not, to pay the premium price. It is also 
really important to pay attention to the quantity of butter sold since the butter market is estimated weak.

Another essential part of the KariGhana Alliance business consists of the reliance on coordinators. They are essential for this Social Business because they are its point of contact with women. Equipped with their "all road" motorcycle and their knowledge of different local dialects, the KariGhana Alliance coordinators ride to see the communities they have been assigned to. Some of their job tasks are to provide training, monitor inventory of the different communities, register new women in the tracking software, and much more.

\section{Building a SBSC}

With all these information in their laptops, the consultant team was ready to start the SBSC pilot project. The team should show how KariGhana Alliance could reconcile its two main goals: to improve the women's quality of life and to achieve the break even to guarantee the sustainability of the social business. So, where should they start? 